\title{
Time-Varying Effective Connectivity during Visual Object Naming as a Function of Semantic Demands
}

\author{
Claudia Poch, ${ }^{1} \oplus^{-M a r t a ~ I . ~ G a r r i d o, ~}{ }^{2,3,4}$ José Manuel Igoa, ${ }^{5}$ Mercedes Belinchón, ${ }^{5}$ Irene García-Morales, ${ }^{6,7}$ \\ and Pablo Campo ${ }^{5}$ \\ ${ }^{1}$ Department of Biological and Health Psychology, Autonoma University of Madrid, 28049 Madrid, Spain, ${ }^{2}$ Centre for Advanced Imaging, ${ }^{3} \mathrm{Queensland}$ \\ Brain Institute, and ${ }^{4}$ Australian Research Centre of Excellence for Integrative Brain Function, The University of Queensland, Brisbane, Queensland 4072 \\ Australia, ${ }^{5}$ Department of Basic Psychology, Autonoma University of Madrid, Madrid, Spain, ${ }^{6}$ Hospital Ruber Internacional, Epilepsy Unit, Neurology \\ Department, 28034 Madrid, Spain, and 7University Hospital of San Carlos, Epilepsy Unit, Neurology Department, 28040 Madrid, Spain
}

Accumulating evidence suggests that visual object understanding involves a rapid feedforward sweep, after which subsequent recurrent interactions are necessary. The extent to which recurrence plays a critical role in object processing remains to be determined. Recent studies have demonstrated that recurrent processing is modulated by increasing semantic demands. Differentially from previous studies, we used dynamic causal modeling to model neural activity recorded with magnetoencephalography while 14 healthy humans named two sets of visual objects that differed in the degree of semantic accessing demands, operationalized in terms of the values of basic psycholinguistic variables associated with the presented objects (age of acquisition, frequency, and familiarity). This approach allowed us to estimate the directionality of the causal interactions among brain regions and their associated connectivity strengths. Furthermore, to understand the dynamic nature of connectivity (i.e., the chronnectome; Calhoun et al., 2014) we explored the time-dependent changes of effective connectivity during a period (200-400 ms) where adding semantic-feature information improves modeling and classifying visual objects, at $50 \mathrm{~ms}$ increments. First, we observed a graded involvement of backward connections, that became active beyond $200 \mathrm{~ms}$. Second, we found that semantic demands caused a suppressive effect in the backward connection from inferior frontal cortex (IFC) to occipitotemporal cortex over time. These results complement those from previous studies underscoring the role of IFC as a common source of top-down modulation, which drives recurrent interactions with more posterior regions during visual object recognition. Crucially, our study revealed the inhibitory modulation of this interaction in situations that place greater demands on the conceptual system.

Key words: dynamic causal modeling; effective connectivity; recurrent interactions; top-down modulation; visual object naming

\section{Introduction}

Current conceptions of visual object processing consider that the ventral visual pathway (Ungerleider and Mishkin, 1982) is responsible for the transformation from visual image to meaningful object (Lupyan et al., 2010; Carlson et al., 2014; Mur, 2014). Anatomically, this route consists of an interconnected network of cortical regions moving rostrally from the occipitotemporal cortex (OTC) to the anterior-inferior temporal cortex, extending into the inferior frontal cortex (IFC; Kravitz et al., 2013). Information flow across this stream is supported by distinct associative

Received Dec. 1, 2014; revised April 30, 2015; accepted May 3, 2015.

Author contributions: J.M.I., M.B., I.G.-M., and P.C. designed research; C.P., I.G.-M., and P.C. performed research; C.P., M.I.G., J.M.I., M.B., and P.C. analyzed data; C.P., M.I.G., J.M.I., M.B., I.G.-M., and P.C. wrote the paper.

This work was supported by the Spanish Ministry of Science and Innovation, Grant SAF2011-27920 to I.G.-M.,P.C. was supported by a Ramon y Cajal Fellowship from the Spanish Ministry of Science and Innovation (RYC-201005748), C.P. was supported by Spanish Ministry of Science and Education (AP2009-4131), and M.I.G. is supported by an Australian Research Council Discovery Early Career Researcher Award (DE1301011393) and the Australian Research council Centre of Excellence for integrative Brain Function (ARC Centre Grant CE140100007).

The authors declare no competing financial interests.

Correspondence should be addressed to Dr. Pablo Campo, Departamento de Psicología Básica, Universidad Autónoma de Madrid, Campus de Cantoblanco, 28049 Madrid, Spain. E-mail: pablo.campo@uam.es.

DOI:10.1523/JNEUROSCI.4888-14.2015

Copyright $\odot 2015$ the authors $\quad 0270-6474 / 15 / 358768-09 \$ 15.00 / 0$ white matter fibers. Although tractography cannot determine the direction of axonal projections in a tract (Acosta-Cabronero et al., 2011), studies of dynamic interactions showed that after an initial feedforward projection, recurrent processing constitutes a mechanism for the integration of higher-level semantic information with visual information (Bar et al., 2006; Chan et al., 2011; O'Reilly et al., 2013; Clarke et al., 2014; Mur and Kriegeskorte, 2014). The extent to which recurrent interactions critically contribute to object understanding is modulated by task-induced processing demands (Harel et al., 2014; Tang et al., 2014), and in particular by the specificity of semantic processing required by the task (Clarke et al., 2011, 2014; O'Reilly et al., 2013; Cichy et al., 2014; Harel et al., 2014). So that higher-order anterior areas are required for fine-grained differentiation processes (Moss et al., 2005; Clarke and Tyler, 2014; Clarke et al., 2014), which exert top-down influence upon posterior regions, instantiating recurrent interactions (Tang et al., 2014). Most of these studies have inferred top-down influences by indirect means (i.e., delays in the response latency between conditions). Here, we applied dynamic causal modeling (DCM) for evoked responses (David et al., 2006), to model the activity of brain regions recorded with magnetoencephalography (MEG) while participants named visual 
objects at the basic level, which were subsequently separated into a high- and low-demanding subsets according to values of psycholinguistic variables (i.e., familiarity, frequency, and age of acquisition) associated with the objects to be named (Krishnan et al., 2014). DCM allows us to understand how information propagates through brain regions (Kahan and Foltynie, 2013) by estimating the directionality of the causal interactions among brain regions and their associated connectivity strengths (Bianchi et al., 2013). The effects of psycholinguistic variables reflect differences in processing demands, which correlate with differences in the neurophysiologic processes underlying particular cognitive operations (Ellis et al., 2006; Graves et al., 2007). As the focus was on the role of recurrent connections, we compared functional architectures with and without backward connections (Garrido et al., 2007), and tested their contribution during visual naming of high- and low-semantically demanding items. Crucially, we explored the time-varying patterns of coupling among regions (the chronnectome; Calhoun et al., 2014), and estimated the effective connectivity during a period (beyond $200 \mathrm{~ms}$ ) where adding semantic-feature information improves modeling and classifying visual objects (Clarke et al., 2014) at $50 \mathrm{~ms}$ increments. By comparing the models, we tested the contribution of feedforward and feedback interactions (Penny et al., 2010) at different moments in time (Calhoun et al., 2014).

\section{Materials and Methods}

Subjects

Fourteen adult subjects ( 9 female; mean age 36.64 years, $S D=8.42$ years; mean formal education 16 years, $\mathrm{SD}=1.84$ years), without any history of neurological or psychiatric illness, volunteered for participation in the study, and gave written consent in accordance with the Declaration of Helsinki, after the nature of the procedures involved had been explained to them. Participants were right handed according to the Edinburgh Handedness Inventory (Oldfield, 1971). Of note, data from 10 of the participants were part of a previous study (Campo et al., 2013).

\section{Naming task}

Participants were required to name aloud black and white line drawings of common objects at the basic level (Clarke et al., 2011, 2014), thus ensuring that participants processed the objects at an individual level (Mur, 2014). The study used images from a visual confrontation naming task that was created in a previous study (Campo et al., 2013) by combining images from the Cambridge 64-item naming task (Bozeat et al., 2000) and the 175-item Philadelphia Naming Test (Roach et al., 1996). Images belonging to both tests were presented only once. From the pool of items, two subsets of 64 items of visual objects that differed in their semantic demands, operationalized in terms of the values of basic psycholinguistic variables associated with the objects to be named; specifically age of aquisition (AoA), frequency of occurrence, and concept familiarity (Krishnan et al., 2014 used a similar approach). These variables are significantly correlated among them, especially in large sets of pictorial stimuli (Graves et al., 2007; Wilson et al., 2009; Strijkers et al., 2010; Woollams, 2012). This fact, along with the consideration that their influence has been commonly accounted for by the degree of representation and connection in a distributed-representation network (Steyvers and Tenenbaum, 2005; Ellis et al., 2006; Patterson, 2007), led us to evaluate the modulation of connectivity using two different sets of objects showing a typical distribution across those psycholinguistic dimensions. Thus, items were sorted by concept familiarity, according to Spanish available norms (Sanfeliú and Fernández, 1996; Cuetos et al., 1999; Sebastián et al., 2000), and differed not only in terms of familiarity, but also on AoA, and frequency of occurrence (all $p<0.001$ ). Concept familiarity was rated on a five-point scale from $1=$ unfamiliar to $5=$ highly familiar. Frequency was taken from the Alameda and Cuetos' (1995) dictionary of frequencies, which is based on a corpus of written texts comprising 2 million words (Cuetos et al., 1999). Both sets contain an equal number of living (32 exemplars) and nonliving objects (32 exemplars), which were
Table 1. Characteristics of the stimuli comprising the 64 low-demanding and 64 high-demanding conditions

\begin{tabular}{lcc}
\hline Variable & Low-demanding & High-demanding \\
\hline $\begin{array}{l}\text { Frequency of use } \\
\quad \text { Mean }\end{array}$ & 156.47 & 46.30 \\
$\quad$ SD & 196.24 & 65.51 \\
Concept familiarity & & \\
$\quad$ Mean & 4.06 & 2.04 \\
$\quad$ SD & 0.54 & 0.60 \\
Age of acquisition (estimated in years) & & \\
$\quad$ Mean & 4.21 & 5.11 \\
SD & 0.92 & 1.31 \\
\hline
\end{tabular}

Note: concept familiarity was rated on a five-point scale from $1=$ unfamiliar to $5=$ highly familiar. Frequency was taken from the Alameda and Cuetos' (1995) dictionary of frequencies, which is based on a corpus of written texts comprising 2 million words (Cuetos et al., 1999). Values according to Spanish available norms (Sanfeliú and Fernández, 1996; Cuetos et al., 1999; Sebastián et al., 2000). Both sets contain an equal number of living (32 exemplars) and nonliving objects (32 exemplars).

also matched on picture complexity. As a measure of perceptual complexity we used JPEG size (Müller et al., 2008). Characteristics of the stimuli for both conditions are shown in Table 1. Conditions were labeled as "high-demanding" and "low-demanding" (Graves et al., 2007). The task was adapted for scanning purposes, such that in each trial participants first saw a fixation cross located centrally for $1000 \mathrm{~ms}$, which was followed by a picture lasting in the display $1000 \mathrm{~ms}$. Then, a question mark was shown indicating that participants have to overtly name the presented object as accurately as possible (Laaksonen et al., 2012). The next trial began when participants provided an answer or after $5000 \mathrm{~ms}$ elapsed. Picture naming performance was calculated in terms of the proportion of correct responses.

\section{Data acquisition and analysis}

Magnetoencephalography recordings. MEG data were obtained using a whole-head 306 channel Vector-view system (Elekta-Neuromag), consisting of 102 magnetometers and 204 orthogonal planar gradiometers. The signal was recorded continuously at a sampling rate of $600 \mathrm{~Hz}$ with an online bandpass filter from 0.1 to $200 \mathrm{~Hz}$. The head position relative to the sensor array was measured at the beginning of the session using four head position indicator coils. Before the recording session, the anatomical landmarks (nasion, and left and right periauricular) and extra points of the head shape were obtained using a 3D digitizer (Fastrak Polhemus). In addition, vertical electro-oculogram was recorded, with electrodes located supraorbitally and infraorbitally.

Static band channels were detected using the MaxFilter program (v2.2.10; Elektra-Neuromag), and were interpolated. The number of excluded channels varied between one and four $(\mathrm{M}=2, \mathrm{SD}=1)$, which were found in nine participants. Artifacts were suppressed by applying a temporally extended signal-space separation method (Taulu and Hari, 2009), using a 10 s correlation window with a correlation limit of 0.9 .

Magnetoencephalography data preprocessing and source localization. Data were preprocessed and subsequently analyzed using Statistical Parametric Mapping (SPM8) academic software (Wellcome Trust Centre for Neuroimaging, UCL; http://www.fil.ion.ucl.ac.uk/spm/; Litvak et al., 2011 provides a detailed description) implemented in MATLAB (MathWorks). Data analyses were conducted using the 204 planar gradiometer channels. The continuous time series for each participant was processed with a Butterworth bandpass filter at $3-30 \mathrm{~Hz}$ and then were epoched off-line to obtain $500 \mathrm{~ms}$ data segments corresponding to a -100 to $400 \mathrm{~ms}$ peristimulus time. We analyzed epoched data during this period for each trial, for each condition (i.e., high-demanding and lowdemanding), for each participant. Trials including eye blinks, or other myogenic or mechanical artifacts were removed using the thresholding criteria implemented in SPM8 [trials containing signal strength exceeding $3000 \mathrm{fT} / \mathrm{cm}$ (Furl et al., 2014)] and $\mu 100$ at electrooculogram channels were excluded). Epochs were baseline corrected from -100 to $0 \mathrm{~ms}$, and then averaged.

The next step was to estimate the cortical origin of the neuronal response. For source reconstruction, a multiple sparse priors routine (as implemented in SPM8) was used (Friston et al., 2008), which uses 512 
a

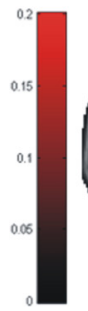

High-demanding condition
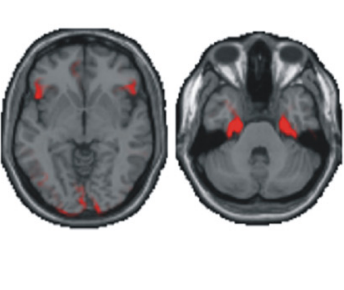
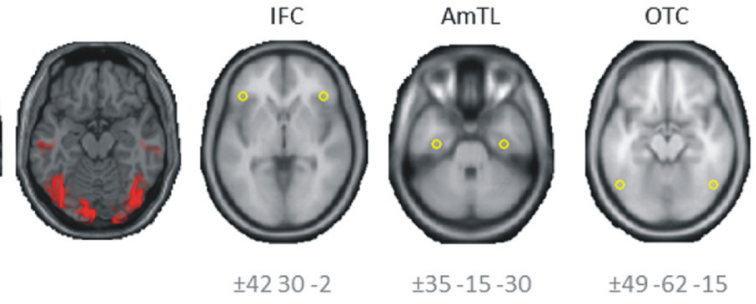
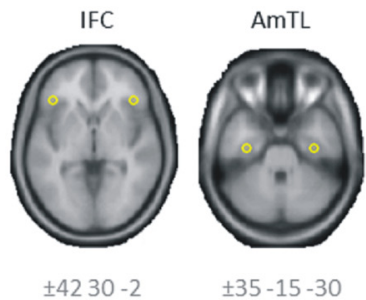

OTC

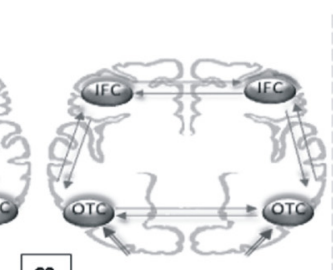

C3

C4

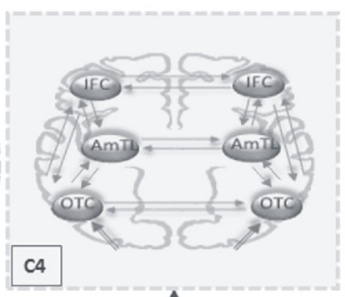

Low-demanding condition
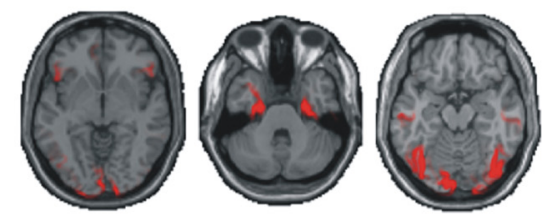

b
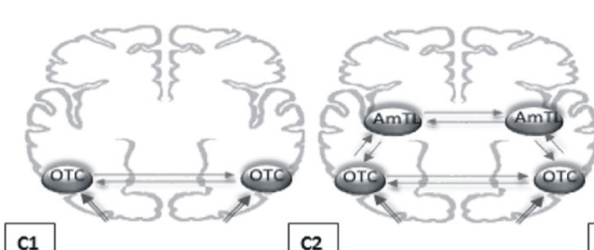

C2

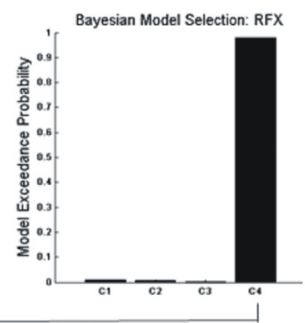

C
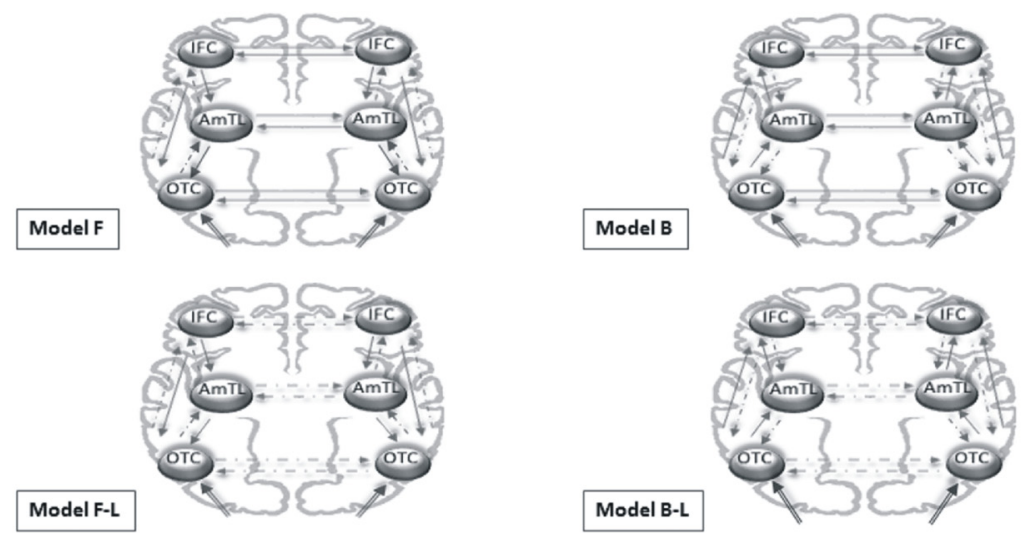

$\uparrow$

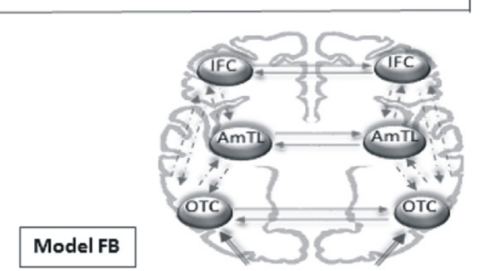

Figure 1. $\quad \boldsymbol{a}$, Axial views of the source localization for the grand-mean responses averaged over high- (left) and low-demanding conditions (right) projected into MNI voxel space and superimposed on the template structural MRl image. Sources of activity (middle), modeled as dipoles (estimated posterior moments and locations) superimposed on an MRI of a standard brain in MNI space, and their coordinates as included in the DCM analysis. $\boldsymbol{b}$, Outline of the four DCM models for the first phase of effective connectivity analysis shown on axial brain schematics. The best model was selected using random-effects BMS (see Materials and Methods). c, Illustration of the models estimated and compared in the second phase of DCM analyses, which differed in the modulatory effects (i.e., forward, backward, and lateral) by the semantic demands. Modulated connections are shown with dashed arrows. Driving inputs are shown by stripped arrows. F, Forward; F-L, forward and lateral; B, backward; B-L, backward and lateral; FB, forward and backward; FB-L, forward, backward, and lateral.

patches of activation that are iteratively reduced until an optimal number and location of active patches are found using a Bayesian greedy search. A 8196 vertex template cortical mesh in canonical Montreal Neurological Institute (MNI) anatomical space served as a brain model for the estimation of the current source distribution (Mattout et al., 2007). Coregistration to the MNI was done using the three anatomical landmarks, as well as the extra-digitalized points (i.e., headshape). This dipole mesh was used to calculate the forward solution using a digitalized single-shell model. The inverse solution was calculated over a time window from 0 to $400 \mathrm{~ms}$ after stimulus onset for each condition, and averaged over participants. As pointed by Strijkers et al. (2010), MEG studies of overt picture naming have shown that reliable measures of brain activity can be taken at least until $400 \mathrm{~ms}$ after picture onset (Hart et al., 1998; Maess et al., 2002; Clarke et al., 2011, 2013, 2014; Mousas et al., 2015). Furthermore, as two previous studies have estimated the onset of semantic processing of visual objects to be $\sim 200 \mathrm{~ms}$ (Hart et al., 1998; Clarke et al., 2014), we explored this time interval at $50 \mathrm{~ms}$ increments, from 200 to $400 \mathrm{~ms}$. Source reconstructions were interpolated into MNI voxel space and analyzed using statistical parametric mapping (Kilner and Friston, 2010), as described by Moran et al. (2013). A contrast of high-demanding versus low-demanding based on the evoked related fields (ERF) was conducted at $p<0.005$ (uncorrected) using a paired $t$ test.

Effective connectivity analysis: dynamic causal modeling. DCM is a hypothesis-driven method that relies on the specification of a plausible biophysical and physiological model of interacting brain regions
(Stephan and Friston, 2007), and is therefore appropriate for situations where there is a priori knowledge and experimental control over the system of study (Cardin et al., 2011; Seghier et al., 2011). Bayesian model selection (BMS) is used to compare different models or to find the model with best evidence (Penny et al., 2004). This allows one to compare alternative hypotheses (models) of how measured data are caused (Friston, 2011). Thus, a critical factor is the architecture of the models, that is, the nodes and their interconnections (Rudrauf et al., 2008). As mentioned above, the selection of sources or nodes of the network architectures was based on inverse solutions (i.e., multiple sparse priors; Friston et al., 2008), therefore optimized for the particular subjects studied. Sources were chosen by the apparent signal propagation along the cerebral cortex observed in source reconstruction results (Rudrauf et al., 2008), which were reliably present across participants in both conditions (Kawabata Duncan et al., 2014; Woodhead et al., 2014; Fig. 1a). Six sources were identified and then modeled as equivalent current dipoles positioned symmetrically in each hemisphere, in a canonical brain (MNI) space, with prior mean location coordinates $(x, y, z)$ at: OTC: $-49,-62,-15$ (left); 49, $-62,-15$ (right); anteromedial temporal lobe (AmTL): $-35,-15,-30$ (left); 35, - 15, - 30 (right); and IFC: $-42,30$, -2 (left); 42, 30, -2 (right) (Fig. 1 $a$; Campo et al., 2013). These sources were optimized at an individual level during DCM inversion using distributed dipoles, and the forward solution from the source localization (Moran et al., 2014). These anatomical regions are in fine agreement with the results from previous MEG studies of visual object naming (Clarke et 
al., 2011, 2013, 2014; Campo et al., 2013; Mousas et al., 2015). DCM analyses were performed using the most recent version of SPM12.

We followed the procedure described by Woodhead et al. (2014) as the structure of their experiment is very similar to ours. Accordingly, we first developed four competing model configurations that varied in number of sources and regional location. Configuration 1, included sources in left and right OTC only; Configuration 2, with left and right OTC, and AmTL sources; Configuration 3, with left and right OTC, and IFC sources; and Configuration 4, with left and right OTC, AmTL, and IFC sources (Fig. $1 b$ ). In all cases models were left hemisphere-right hemisphere symmetric (David et al., 2011), and the OTC bilaterally served as input region (Salmelin and Kujala, 2006; Heim et al., 2009; Schurz et al., 2014). All possible forward, backward, and homotopic lateral connections between sources were included in the models (Fig. 1b). These interconnections followed anatomical-functional evidences (for a similar approach, see Rudrauf et al., 2008). Specifically, occipitotemporal regions have been shown to be functionally connected with IFC during visual object processing (Bar et al., 2006), and anatomically by means of the inferior fronto-occipital fasciculus (Catani and Thiebaut de Schotten, 2008; Dick and Tremblay, 2012). AmTL has been shown to be functionally connected with occipitotemporal regions and with IFC (Pascual et al., 2015), underpinned by structural connections by means of the inferior longitudinal fascicle, and the uncinate fascicle, respectively (Catani and Thiebaut de Schotten, 2008; Duffau et al., 2013; Von Der Heide et al., 2013; Bouhali et al., 2014; Fan et al., 2014). Additionally, interhemispheric connections between homotopic regions have been extensively documented (Seacord et al., 1979; Clarke, 2003; Turken and Dronkers, 2011; Berlucchi, 2014). These models were inverted per participant for all trials (high- and low-demanding conditions) over the first $400 \mathrm{~ms}$. We performed a random-effect (RFX) BMS procedure (Penny et al., 2004) to select the architecture that best explained the electromagnetic responses, based on the posterior exceedance probability $(x p)$. This method quantifies how likely a specific model generated the data of a random subject in the context of a group of subjects, and is preferred when optimal models can vary across participants (Seghier et al., 2010; Stephan et al., 2010). Having established the model structure that provided the best fit to the data, in a second step, we estimated the modulatory effects on effective connectivity between sources for a different subset of connections (i.e., forward backward or both) induced by semantic demand (i.e., high vs low; Seghier et al., 2011; Woodhead et al., 2014). This was accomplished by Bayesian model averaging (BMA) over five successive $50 \mathrm{~ms}$ time windows, 1-200, 1-250, 1-300, 1-350, and 1-400 ms, covering the period where adding semantic-feature information improves modeling and classifying visual objects (Clarke et al., 2014). A requirement of the DCM analysis is that all time windows incorporate the time at which the stimulus was presented (Woodhead et al., 2014). This dynamic view of coupling has recently been coined as "chronnectome" (Calhoun et al., 2014).

\section{Results}

\section{Behavioral results}

Differences in performance accuracy between conditions were analyzed by a paired $t$ test. Participants were more accurate on the low-demanding condition $(\mathrm{M}=97.09, \mathrm{SD}=2.44)$ than in the high-demanding condition $\left(\mathrm{M}=93.06, \mathrm{SD}=3.02 ; t_{(13)}=4.57\right.$, $p<0.001)$.

\section{Source space analysis}

We observed that both conditions consistently activated several regions in the ventral stream, but no differences were found between them $(p<0.005$, uncorrected; Fig. 1a).

\section{BMS}

BMS (RFX) revealed that the optimal architecture (i.e., the model with the highest $x p$ ) included sources in the left and right OTC, AmTL, and IFC sources $(x p=0.979$; Fig. $1 b)$.

\section{Time-varying changes in effective connectivity between conditions}

The winning architecture obtained in the previous step was used as the basic structure to estimate the modulatory effects of semantic demands on effective connectivity. As our main interest was to determine the role of recurrent dynamics, six competing models differed in the presence or absence of modulatory effects on backward connections. This allowed us to test whether the observed evoked responses were best explained by a model operating in a forward manner or whether inclusion of backwards connections improved the explanation of the data (Garrido et al., 2007; Furl et al., 2014). Additionally, modulation of lateral connections linking homologous areas was also included. Differences between conditions were evaluated by allowing connections to be modulated (David et al., 2011). Accordingly, six competing models, each representing a different way on how connections between sources are modulated, were fitted to each participant's ERF data (Auksztulewicz and Friston, 2015): forward; forward plus lateral; backward; backward plus lateral; forward and backward; forward and backward plus lateral (Fig. 1c). Finally, to explore the dynamics in the effective connectivity within the network as a function of task demands, this is, timevarying changes on functional architecture configuration and on the connectivity strengths (Calhoun et al., 2014; Clarke et al., 2014; Fedorenko and Thompson-Schill, 2014; Murray et al., 2014; Woodhead et al., 2014), models were specified and inverted separately from stimulus onset to a variable poststimulus time, ranging from 200 to $400 \mathrm{~ms}$, in 50 ms steps (Garrido et al., 2007; Woodhead et al., 2014). BMS was done at the family level (Penny et al., 2010). In this case, the $x p$ values represent the evidence of each family of models instead of the evidence of each individual model (Seghier et al., 2011). We defined three families that grouped models according to the dominant direction of modulatory effects with no overlap: forward (Fwd), backward (Bwd), and forward and backward (Fwd-Bwd; Garrido et al., 2007; Schurz et al., 2014; Fig. 2b). A BMA procedure (Penny et al., 2010) was then used to compute posterior means of connectivity parameters for each subject (Seghier et al., 2011). BMA estimate the average strength of the connectivity parameters of all the models tested, weighted by their posterior probabilities, so that the contribution of models with weak evidence is minimized (Seghier et al., 2011). This procedure generates a distribution of the model parameters that is proportional to the likelihood of each model given the data (Richardson et al., 2011). From the different sets of parameters estimated by DCM, we focused on modulatory parameters that measure the changes in effective connectivity induced by the experimental conditions (Cardin et al., 2011; Kawabata Duncan et al., 2014). Hence, parameters values for the modulations calculated during the BMA were obtained for each subject and extracted to make statistical inferences at the group level with repeated-measures ANOVA.

\section{Family selection results}

BMS (RFX) revealed that the family that provides the best explanation of the data varied across time. In the 1-200 ms time window, the family Fwd was clearly superior to all other families $(x p=0.931)$. In the following three time-windows (1-250, 1-300, and 1-350 ms) the family Fwd-Bwd was considered the winning family $(x p=0.782, x p=0.439, x p=0.875$, respectively; Fig. $2 b$ ). However, in the time window 1-300 ms, despite the fact that family Fwd-Bwd had the greatest $x p$, it could not be considered as clearly superior to the other families. Note that the best three models belonged to each of the three families, representing 
a Random-effect Bayesian Model Selection

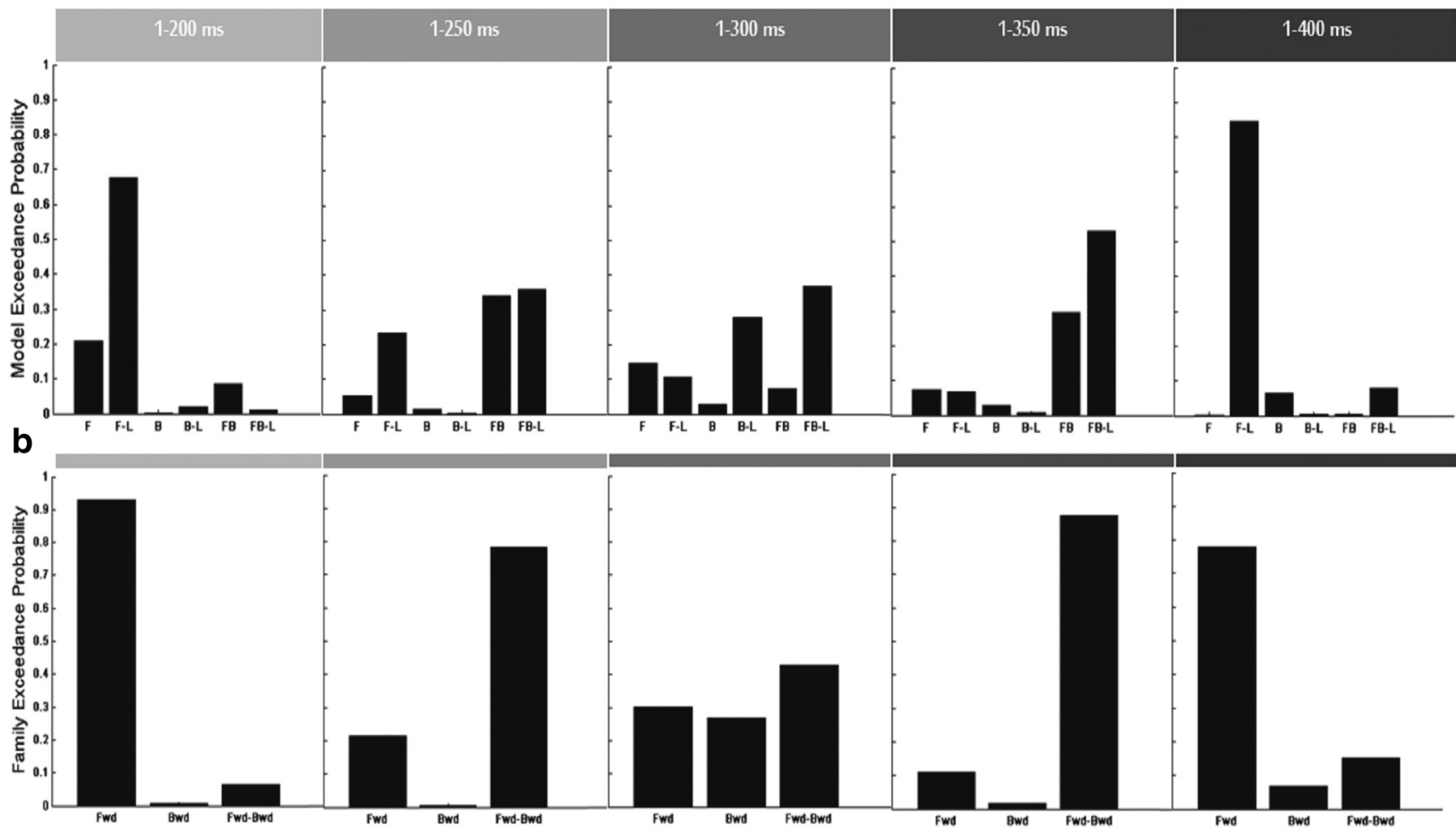

Figure 2. Random-effects BMS in five time windows. The bar graphs plot the exceedance probability at the (a) model level and (b) family level. F, Forward; F-L, forward and lateral; B, backward; $\mathrm{B}-\mathrm{L}$, backward and lateral; FB, forward and backward; FB-L, forward, backward, and lateral.

$79 \%$ of $x p$ (Fig. 2a). This indicated that it was not possible to clearly distinguish between families (David et al., 2011). Thus, in this case, the three families were considered as winning families, and were used to extract the modulatory connections calculated during a BMA procedure (Seghier et al., 2011; for a similar procedure, see David et al., 2011). In the 1-400 ms time-window, family Fwd had again the greatest evidence ( $x p=0.779$; Fig. $2 b)$.

\section{Modulatory effects of semantic demands: model parameters results}

We conducted a series of repeated-measures ANOVA with modulatory parameters as the dependent measures, and condition (high-demanding vs low-demanding), hemisphere (left and right), and latency $(200,250,300,350$, and $400 \mathrm{~ms})$ as the withinsubject factors. Note that for backward connections, latency only had three levels (250, 300, and $350 \mathrm{~ms})$. Analyses were performed using SPSS 18.0. Effects were considered statistically significant when $p<0.05$ after Bonferroni correction. Accordingly, SPSS Bonferroni adjusted $p$ values are quoted (Rytsar et al., 2011).

The only modulatory effect that reached significance was observed in the backward connection from IFG to OTC (Fig. 3). Specifically, a main effect of Condition was observed $\left(F_{(1,13)}=\right.$ 5.12, $\left.p<0.05 ; \eta^{2}=0.283\right)$. Further comparisons indicated that there was a significant increase in the negative coupling in the backward connection from IFC to OTC in the high- (Mean = $-0.085, \mathrm{SEM}=0.029)$ as compared with the low-demanding condition $($ Mean $=0.044, \mathrm{SEM}=0.032 ; p<0.05$ corrected). Although the coupling in the backward connection from IFC to OTC was negative in the high- compared with low-demanding condition over time, this was especially marked in the $1-350 \mathrm{~ms}$ time window, when there was a significant increase in the nega- tive coupling in the backward connection from left IFC to left OTC in the high- $($ Mean $=-0.23$, SEM $=0.087)$ compared with low-demanding condition $\left(\right.$ Mean $=0.068, \mathrm{SEM}=0.086 ; t_{(13)}=$ $2.32, p<0.05)$. Additionally, we observed a trend for a negative correlation between the backward connection from left IFC to left OTC and performance in the high-demanding condition in the $1-350$ ms time window $(r=-0.49, p=0.075)$.

\section{Discussion}

Using DCM for evoked magnetic fields (David et al., 2006) we were able to determine the extent to which semantic demands modulate the dynamics in the recurrent interactions during visual object naming. Semantic demands were operationalized by differences in significant psycholinguistic variables of the objects to be named (Graves et al., 2007). Interestingly, we observed a variation in the modulatory effects over time. Specifically, the DCM family with modulatory effects on forward connection only (family Fwd) had greater evidence than families including modulatory effects on backward connections (families Bwd and FwdBwd) in the 1-200 ms time window (DiCarlo et al., 2012). In the following three consecutive time windows $(1-250,-300,-350$ $\mathrm{ms})$, modulatory effects on recurrent connections became active, as family Fwd-Bwd appeared as the most likely, especially in the 1-350 ms time-window. Modulatory effects on backward connections were no longer relevant in the 1-400 ms time-window, when family Fwd had again the greater evidence (Fig. 2). In addition, we also observed that the contribution of interhemispheric connections appears to be relevant, as in each time window the configurations that better explain the data include this type of connection (Clarke, 2003). These interactions could contribute to coordinate and integrate specific activity generated 
$1-250 \mathrm{~ms}$

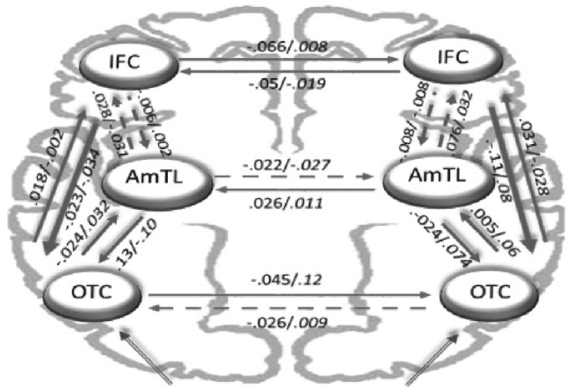

$1-300 \mathrm{~ms}$

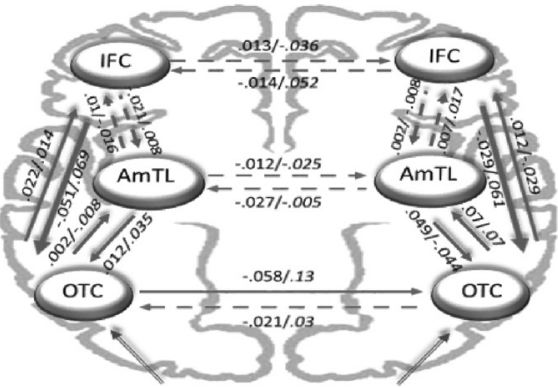

$\mathrm{RH}$

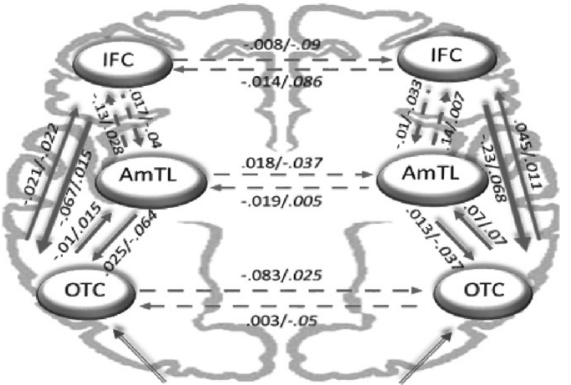

RH

$1-350 \mathrm{~ms}$

L

Figure 3. Schematic representation of the BMA results in the time windows where recurrent interactions became active: 1-250, 1-300, and 1-350 ms. Arrows represent the fixed effective connectivity that is present in the system regardless of the modulatory effect. Normal arrows represent positive (i.e., excitatory) connections; dashed arrows represent negative (i.e., inhibitory) connections. Values represent the modulatory effect of semantic demands on connection strength. Values for the high-demanding condition are represented by normal font and for the lowdemanding condition by italics. Thick lines represent significant modulatory effect of semantic demands. Note that the significant modulation between IFC and OTC was observed over time. Driving inputs are shown by stripped arrows. LH, Left hemisphere; RH, right hemisphere.

by both hemispheres (Mima et al., 2001; Seghier et al., 2011); for instance a conceptual versus physical hemispheric specialization (Harel et al., 2014). The observed time course of feedforward and backward connections is largely consistent with the notion of an initial feedforward sweep (Thorpe et al., 1996; Riesenhuber and Poggio, 1999) enabling a coarse semantic processing (Wu et al., 2015), followed (>200 ms) by a recurrent processing supporting the formation of increasingly complex semantic representations (Lamme and Roelfsema, 2000; Hochstein and Ahissar, 2002; Schendan and Maher, 2009; Clarke et al., 2011, 2014; Ghodrati et al., 2014; Harel et al., 2014; Khaligh-Razavi and Kriegeskorte, 2014). Of particular interest to current findings, a recent MEG study of visual object recognition showed a similar timing of feedforward and backward interactions, with the latter being observed at 210-250 ms, but not earlier, when feedforward were predominant (Ahlfors et al., 2015). A similar modulation of the contribution of backward connections to evoked responses as a function of peristimulus time was demonstrated by Garrido et al. (2007) during a mismatch negativity task, when backward connections became essential after $220 \mathrm{~ms}$. Additional support comes from a study that interfered visual recognition at 100 and 220 ms by applying transcranial magnetic stimulation over the occipital cortex (Camprodon et al., 2010). Domain or basic level naming was impaired at different moments, concluding that the $220 \mathrm{~ms}$ time window corresponded to a recurrent stage of visual processing (Roelfsema et al., 2002; Heinen et al., 2005; Wokke et al., 2012; Wu et al., 2015).

When focusing on specific interactions between sources, crucially, we observed that semantic demands significantly modulated the involvement of the positive (i.e., excitatory) recurrent processing from IFC to OTC over time (Fig. 3). Recurrent interactions involving IFC and posterior brain regions have been reported in several studies of visual object processing (Freedman et al., 2003; Bar et al., 2006; Ghuman et al., 2008; Schendan and Maher, 2009; Buffalo et al., 2010; Gilbert and Li, 2013; Harel et al., 2014; Murray et al., 2014). Top-down influences of IFC are considered to modulate the activity in posterior regions by biasing processing only to the most likely candidates, and thus facilitate detailed recognition of objects (Fenske et al., 2006; Schendan and Maher, 2009; Clarke et al., 2011; Trapp and Bar, 2015). Specifically, Bar et al. (2006; Chaumon et al., 2014) showed an enhanced phase synchronization between orbitofrontal cortex and the fusiform gyrus during an object recognition task. Differentially from this study, we used a method (DCM) that allowed us to examine the directionality of the causal interactions among brain regions, and to determine whether they are inhibitory or excitatory (Cardin et al., 2011). Our results showed that increased semantic demands caused a negative modulation in the excitatory backward connection from IFC to OTC over time, which was more evident in the left hemisphere in the $1-350 \mathrm{~ms}$ time window. Interestingly, we found that performance on the high-demanding condition showed a trend $(r=-0.49, p=0.075)$ to be negatively correlated with the backward connection from left IFC to left OTC in the 1-350 ms time window, such that more negative modulation was associated with better performance. Inhibitory effects in top-down signals from high level areas to lower level areas have been observed during visual processing of meaningful stimuli (Chen et al., 2009; Cardin et al., 2011) and lexical decision (Deng et al., 2012; Xu et al., 2015), that could result in more efficient processing (Ghuman et al., 2008). Recently, O'Reilly et al. (2013) described a biological model of the ventral visual pathway that provides evidence about the importance of recurrent inhibitory mechanisms in visual object recognition in situations that impoverished the image, that is, situations in which recognition is more difficult (Tang et al., 2014). Less frequent, atypical, unfamiliar and/or late-acquired concepts are thought to form weaker semantic associations and have less-detailed representations than more frequent/familiar or early acquired ones (Hirsch and Funnell, 1995; Lambon Ralph et al., 1998; Rogers et al., 2004; Woollams et al., 2008; Jefferies et al., 2009; Lambon Ralph et al., 2010; Hoffman et al., 2012; Woollams, 2012; Campo et al., 2014). Therefore, the role of the suppressive effect of the backward connection from prefrontal to posterior object-sensitive regions in the high-demanding condition could be to disambiguate the identity of the object to select one object concept from other exemplars (Walther and Koch, 2007; Gerlach and Marques, 2014), thus biasing processing only to the most likely candidates (Schendan and Kutas, 2002; Moss et al., 2005; Schendan and Maher, 2009; Clarke et al., 2011; Deng et al., 2012; Bruffaerts et al., 2013; Wright et al., 2015). This is, in the high-demanding condition object individuation (Gerlach and Marques, 2014) requires a greater inhibition of unintended exemplars (Deng et al., 2012). Compatible with this idea are the results from another study by Clarke et al. (2013), in which they suggested that the selection and retrieval of weakly correlated semantic information 
places greater demands on the conceptual system, driving an increased recruitment of frontal regions.

In summary, we used a method (i.e., DCM) that allows to understand how information propagates through brain regions (Kahan and Foltynie, 2013) by estimating the directionality of the causal interactions among brain regions and their associated connectivity strengths (Bianchi et al., 2013). Crucially, we explored the variation in the modulatory effects of semantic demands during visual-object naming across time, thus providing a dynamic measure of connectivity (Calhoun et al., 2014). We focused on interactions between brain regions across the ventral pathway (i.e., long-range interactions; Bressler and Richter, 2015), whereas recent studies have explored feedback influences as a function of behavioral demands among several occipital areas (Bastos et al., 2015). First, we observed a graded involvement of backward connections, which is largely consistent with the notion of an initial feedforward sweep enabling a coarse semantic processing, followed ( $>200 \mathrm{~ms}$ ) by a recurrent processing supporting the formation of increasingly complex semantic representations (Hochstein and Ahissar, 2002; Schendan and Maher, 2009; Clarke et al., 2011, 2014; Harel et al., 2014; Khaligh-Razavi and Kriegeskorte, 2014). Second, we found that semantic demands caused a suppressive effect in the excitatory backward connection from IFC to OTC over time, which was remarkably evident in the 1-350 ms time window. Thus, current results complement those from previous studies underscoring the role of IFC as a common source of top-down modulation, which drives recurrent interactions with more posterior regions during visualobject recognition (Bar et al., 2006; Trapp and Bar, 2015). Crucially, our results revealed the inhibitory nature of this interaction in situations that place greater demands on the conceptual system (O’Reilly et al., 2013).

\section{References}

Acosta-Cabronero J, Patterson K, Fryer TD, Hodges JR, Pengas G, Williams GB, Nestor PJ (2011) Atrophy, hypometabolism and white matter abnormalities in semantic dementia tell a coherent story. Brain 134:20252035. CrossRef Medline

Ahlfors SP, Jones SR, Ahveninen J, Hämäläinen MS, Belliveau JW, Bar M (2015) Direction of magnetoencephalography sources associated with feedback and feedforward contributions in a visual object recognition task. Neurosci Lett 585:149-154. CrossRef Medline

Alameda JR, Cuetos F (1995) Diccionario de frecuencias de las unidades lingüísticas del español. Oviedo: Servicio de publicaciones de la Universidad de Oviedo.

Auksztulewicz R, Friston K (2015) Attentional enhancement of auditory mismatch responses: a DCM/MEG study. Cereb Cortex. Advance online publication. CrossRef Medline

Bar M, Kassam KS, Ghuman AS, Boshyan J, Schmidt AM, Dale AM, Hämäläinen MS, Marinkovic K, Schacter DL, Rosen BR, Halgren E (2006) Topdown facilitation of visual recognition. Proc Natl Acad Sci U S A 103: 449-454. CrossRef Medline

Bastos AM, Litvak V, Moran R, Bosman CA, Fries P, Friston KJ (2015) A DCM study of spectral asymmetries in feedforward and feedback connections between visual areas V1 and V4 in the monkey. Neuroimage 108: 460-475. CrossRef Medline

Berlucchi G (2014) Visual interhemispheric communication and callosal connections of the occipital lobes. Cortex 56:1-13. CrossRef Medline

Bianchi AM, Marchetta E, Tana MG, Tettamanti M, Rizzo G (2013) Frequency-based approach to the study of semantic brain networks connectivity. J Neurosci Methods 212:181-189. CrossRef Medline

Bouhali F, Thiebaut de Schotten M, Pinel P, Poupon C, Mangin JF, Dehaene S, Cohen L (2014) Anatomical connections of the visual word form area. J Neurosci 34:15402-15414. CrossRef Medline

Bozeat S, Lambon Ralph MA, Patterson K, Garrard P, Hodges JR (2000) Non-verbal semantic impairment in semantic dementia. Neuropsychologia 38:1207-1215. CrossRef Medline
Bressler SL, Richter CG (2015) Interareal oscillatory synchronization in top-down neocortical processing. Curr Opin Neurobiol 31:62-66. CrossRef Medline

Bruffaerts R, Dupont P, Peeters R, De Deyne S, Storms G, Vandenberghe R (2013) Similarity of fMRI activity patterns in left perirhinal cortex reflects semantic similarity between words. J Neurosci 33:18597-18607. CrossRef Medline

Buffalo EA, Fries P, Landman R, Liang H, Desimone R (2010) A backward progression of attentional effects in the ventral stream. Proc Natl Acad Sci U S A 107:361-365. CrossRef Medline

Calhoun VD, Miller R, Pearlson G, Adah T (2014) The chronnectome: time-varying connectivity networks as the next frontier in fMRI data discovery. Neuron 84:262-274. CrossRef Medline

Campo P, Poch C, Toledano R, Igoa JM, Belinchón M, García-Morales I, Gil-Nagel A (2013) Anterobasal temporal lobe lesions alter recurrent functional connectivity within the ventral pathway during naming. J Neurosci 33:12679-12688. CrossRef Medline

Campo P, Poch C, Toledano R, Igoa JM, Belinchon M, Garcia-Morales I, Gil-Nagel A (2014) Visual object naming in patients with small lesions centered at the left temporopolar region. Brain Struct Funct. Advance online publication. CrossRef Medline

Camprodon JA, Zohary E, Brodbeck V, Pascual-Leone A (2010) Two phases of V1 activity for visual recognition of natural images. J Cogn Neurosci 22:1262-1269. CrossRef Medline

Cardin V, Friston KJ, Zeki S (2011) Top-down modulations in the visual form pathway revealed with dynamic causal modeling. Cereb Cortex 21: 550-562. CrossRef Medline

Carlson TA, Simmons RA, Kriegeskorte N, Slevc LR (2014) The emergence of semantic meaning in the ventral temporal pathway. J Cogn Neurosci 26:120-131. CrossRef Medline

Catani M, Thiebaut de Schotten M (2008) A diffusion tensor imaging tractography atlas for virtual in vivo dissections. Cortex 44:1105-1132. CrossRef Medline

Chan AM, Baker JM, Eskandar E, Schomer D, Ulbert I, Marinkovic K, Cash SS, Halgren E (2011) First-pass selectivity for semantic categories in human anteroventral temporal lobe. J Neurosci 31:18119-18129. CrossRef Medline

Chaumon M, Kveraga K, Barrett LF, Bar M (2014) Visual predictions in the orbitofrontal cortex rely on associative content. Cereb Cortex 24:2899_ 2907. CrossRef Medline

Chen CC, Henson RN, Stephan KE, Kilner JM, Friston KJ (2009) Forward and backward connections in the brain: a DCM study of functional asymmetries. Neuroimage 45:453-462. CrossRef Medline

Cichy RM, Pantazis D, Oliva A (2014) Resolving human object recognition in space and time. Nat Neurosci

Clarke S (2003) Complexity of human interhemispheric connections. In: The parallel brain: the cognitive neuroscience of the corpus callosum (Zaidel E, Iacoboni M, eds), pp 47-49. Cambridge, MA: MIT.

Clarke A, Tyler LK (2014) Object-specific semantic coding in human perirhinal cortex. J Neurosci 34:4766-4775. CrossRef Medline

Clarke A, Taylor KI, Tyler LK (2011) The evolution of meaning: spatiotemporal dynamics of visual object recognition. J Cogn Neurosci 23: 1887-1899. CrossRef Medline

Clarke A, Taylor KI, Devereux B, Randall B, Tyler LK (2013) From perception to conception: how meaningful objects are processed over time. Cereb Cortex 23:187-197. CrossRef Medline

Clarke A, Devereux BJ, Randall B, Tyler LK (2014) Predicting the time course of individual objects with MEG. Cereb Cortex. Advance online publication. CrossRef Medline

Cuetos F, Ellis AW, Alvarez B (1999) Naming times for the Snodgrass and Vanderwart pictures in Spanish. Behav Res Methods Instrum Comput 31:650-658. CrossRef Medline

David O, Kiebel SJ, Harrison LM, Mattout J, Kilner JM, Friston KJ (2006) Dynamic causal modeling of evoked responses in EEG and MEG. Neuroimage 30:1255-1272. CrossRef Medline

David O, Maess B, Eckstein K, Friederici AD (2011) Dynamic causal modeling of subcortical connectivity of language. J Neurosci 31:2712-2717. CrossRef Medline

Deng Y, Guo R, Ding G, Peng D (2012) Top-down modulations from dorsal stream in lexical recognition: an effective connectivity FMRI study. PLoS One 7:e33337. CrossRef Medline 
DiCarlo JJ, Zoccolan D, Rust NC (2012) How does the brain solve visual object recognition? Neuron 73:415-434. CrossRef Medline

Dick AS, Tremblay P (2012) Beyond the arcuate fasciculus: consensus and controversy in the connectional anatomy of language. Brain 135:35293550. CrossRef Medline

Duffau H, Herbet G, Moritz-Gasser S (2013) Toward a pluri-component, multimodal, and dynamic organization of the ventral semantic stream in humans: lessons from stimulation mapping in awake patients. Front Syst Neurosci 7:44. CrossRef Medline

Ellis AW, Burani C, Izura C, Bromiley A, Venneri A (2006) Traces of vocabulary acquisition in the brain: evidence from covert object naming. Neuroimage 33:958-968. CrossRef Medline

Fan L, Wang J, Zhang Y, Han W, Yu C, Jiang T (2014) Connectivity-based parcellation of the human temporal pole using diffusion tensor imaging. Cereb Cortex 24:3365-3378. CrossRef Medline

Fedorenko E, Thompson-Schill SL (2014) Reworking the language network. Trends Cogn Sci 18:120-126. CrossRef Medline

Fenske MJ, Aminoff E, Gronau N, Bar M (2006) Top-down facilitation of visual object recognition: object-based and context-based contributions. Prog Brain Res 155:3-21. CrossRef Medline

Freedman DJ, Riesenhuber M, Poggio T, Miller EK (2003) A comparison of primate prefrontal and inferior temporal cortices during visual categorization. J Neurosci 23:5235-5246. Medline

Friston KJ (2011) Functional and effective connectivity: a review. Brain Connect 1:13-36. CrossRef Medline

Friston K, Harrison L, Daunizeau J, Kiebel S, Phillips C, Trujillo-Barreto N, Henson R, Flandin G, Mattout J (2008) Multiple sparse priors for the M/EEG inverse problem. Neuroimage 39:1104-1120. CrossRef Medline

Furl N, Coppola R, Averbeck BB, Weinberger DR (2014) Cross-frequency power coupling between hierarchically organized face-selective areas. Cereb Cortex 24:2409-2420. CrossRef Medline

Garrido MI, Kilner JM, Kiebel SJ, Friston KJ (2007) Evoked brain responses are generated by feedback loops. Proc Natl Acad Sci U S A 104:2096120966. CrossRef Medline

Gerlach C, Marques JF (2014) Visual complexity exerts opposing effects on object categorization and identification. Vis Cogn 22:751-769. CrossRef

Ghodrati M, Rajaei K, Ebrahimpour R (2014) The importance of visual features in generic vs. specialized object recognition: a computational study. Front Comput Neurosci 8:78. CrossRef Medline

Ghuman AS, Bar M, Dobbins IG, Schnyer DM (2008) The effects of priming on frontal-temporal communication. Proc Natl Acad Sci U S A 105: 8405-8409. CrossRef Medline

Gilbert CD, Li W (2013) Top-down influences on visual processing. Nat Rev Neurosci 14:350-363. CrossRef Medline

Graves WW, Grabowski TJ, Mehta S, Gordon JK (2007) A neural signature of phonological access: distinguishing the effects of word frequency from familiarity and length in overt picture naming. J Cogn Neurosci 19:617631. CrossRef Medline

Harel A, Kravitz DJ, Baker CI (2014) Task context impacts visual object processing differentially across the cortex. Proc Natl Acad Sci U S A 111: E962-971. CrossRef Medline

Hart J Jr, Crone NE, Lesser RP, Sieracki J, Miglioretti DL, Hall C, Sherman D, Gordon B (1998) Temporal dynamics of verbal object comprehension. Proc Natl Acad Sci U S A 95:6498-6503. CrossRef Medline

Heim S, Eickhoff SB, Ischebeck AK, Friederici AD, Stephan KE, Amunts K (2009) Effective connectivity of the left BA 44, BA 45, and inferior temporal gyrus during lexical and phonological decisions identified with DCM. Hum Brain Mapp 30:392-402. CrossRef Medline

Heinen K, Jolij J, Lamme VA (2005) Figure-ground segregation requires two distinct periods of activity in V1: a transcranial magnetic stimulation study. Neuroreport 16:1483-1487. CrossRef Medline

Hirsch KW, Funnell E (1995) Those old, familiar things: age of acquisition, familiarity and lexical access in progressive aphasia. J Neurolinguistics 9:23-32. CrossRef

Hochstein S, Ahissar M (2002) View from the top: hierarchies and reverse hierarchies in the visual system. Neuron 36:791-804. CrossRef Medline

Hoffman P, Jones RW, Ralph MA (2012) The degraded concept representation system in semantic dementia: damage to pan-modal hub, then visual spoke. Brain 135:3770-3780. CrossRef Medline

Jefferies E, Patterson K, Jones RW, Lambon Ralph MA (2009) Comprehension of concrete and abstract words in semantic dementia. Neuropsychology 23:492-499. CrossRef Medline
Kahan J, Foltynie T (2013) Understanding DCM: ten simple rules for the clinician. Neuroimage 83:542-549. CrossRef Medline

Kawabata Duncan KJ, Twomey T, Parker Jones 'Ō, Seghier ML, Haji T, Sakai K, Price CJ, Devlin JT (2014) Inter- and intrahemispheric connectivity differences when reading Japanese kanji and hiragana. Cereb Cortex 24: 1601-1608. CrossRef Medline

Khaligh-Razavi SM, Kriegeskorte N (2014) Deep supervised, but not unsupervised, models may explain IT cortical representation. Plos Comput Biol 10:e1003915. CrossRef Medline

Kilner JM, Friston KJ (2010) Topological inference for EEG and MEG data. Ann Appl Stat 4:1272-1290. CrossRef

Kravitz DJ, Saleem KS, Baker CI, Ungerleider LG, Mishkin M (2013) The ventral visual pathway: an expanded neural framework for the processing of object quality. Trends Cogn Sci 17:26-49. CrossRef Medline

Krishnan S, Leech R, Mercure E, Lloyd-Fox S, Dick F (2014) Convergent and divergent fMRI responses in children and adults to increasing language production demands. Cereb Cortex. Advance online publication. CrossRef Medline

Laaksonen H, Kujala J, Hultén A, Liljeström M, Salmelin R (2012) MEG evoked responses and rhythmic activity provide spatiotemporally complementary measures of neural activity in language production. Neuroimage 60:29-36. CrossRef Medline

Lambon Ralph MA, Graham KS, Ellis AW, Hodges JR (1998) Naming in semantic dementia: what matters? Neuropsychologia 36:775-784. CrossRef Medline

Lambon Ralph MA, Sage K, Jones RW, Mayberry EJ (2010) Coherent concepts are computed in the anterior temporal lobes. Proc Natl Acad Sci U S A 107:2717-2722. CrossRef Medline

Lamme VA, Roelfsema PR (2000) The distinct modes of vision offered by feedforward and recurrent processing. Trends Neurosci 23:571-579. CrossRef Medline

Litvak V, Mattout J, Kiebel S, Phillips C, Henson R, Kilner J, Barnes G, Oostenveld R, Daunizeau J, Flandin G, Penny W, Friston K (2011) EEG and MEG data analysis in SPM8. Comput Intell Neurosci 2011:852961. CrossRef Medline

Lupyan G, Thompson-Schill SL, Swingley D (2010) Conceptual penetration of visual processing. Psychol Sci 21:682-691. CrossRef Medline

Maess B, Friederici AD, Damian M, Meyer AS, Levelt WJ (2002) Semantic category interference in overt picture naming: sharpening current density localization by PCA. J Cogn Neurosci 14:455-462. CrossRef Medline

Mattout J, Henson RN, Friston KJ (2007) Canonical source reconstruction for MEG. Comput Intell Neurosci 2007:67613. CrossRef Medline

Mima T, Oluwatimilehin T, Hiraoka T, Hallett M (2001) Transient interhemispheric neuronal synchrony correlates with object recognition. J Neurosci 21:3942-3948. Medline

Moran RJ, Campo P, Symmonds M, Stephan KE, Dolan RJ, Friston KJ (2013) Free energy, precision and learning: the role of cholinergic neuromodulation. J Neurosci 33:8227-8236. CrossRef Medline

Moran RJ, Symmonds M, Dolan RJ, Friston KJ (2014) The brain ages optimally to model its environment: evidence from sensory learning over the adult lifespan. PLoS Comput Biol 10:e1003422. CrossRef Medline

Moss HE, Rodd JM, Stamatakis EA, Bright P, Tyler LK (2005) Anteromedial temporal cortex supports fine-grained differentiation among objects. Cereb Cortex 15:616-627. CrossRef Medline

Mousas A, Simos PG, Rezaie R, Papanicolaou AC (2015) Estimation of regional activation maps and interdependencies from minimum norm estimates of magnetoencephalography (MEG) data. Neuromethods 91: 267-289. CrossRef

Müller MM, Andersen SK, Keil A (2008) Time course of competition for visual processing resources between emotional pictures and foreground task. Cereb Cortex 18:1892-1899. CrossRef Medline

Mur M (2014) What's the difference between a tiger and a cat? From visual object to semantic concept via the perirhinal cortex. J Neurosci 34:1046210464. CrossRef Medline

Mur M, Kriegeskorte N (2014) What's there, distinctly, when and where? Nat Neurosci 17:332-333. CrossRef Medline

Murray JD, Bernacchia A, Freedman DJ, Romo R, Wallis JD, Cai X, PadoaSchioppa C, Pasternak T, Seo H, Lee D, Wang XJ (2014) A hierarchy of intrinsic timescales across primate cortex. Nat Neurosci 17:1661-1663. CrossRef Medline

Oldfield RC (1971) The assessment and analysis of handedness: the Edinburgh inventory. Neuropsychologia 9:97-113. CrossRef Medline 
O’Reilly RC, Wyatte D, Herd S, Mingus B, Jilk DJ (2013) Recurrent processing during object recognition. Front Psychol 4:124. CrossRef Medline

Pascual B, Masdeu JC, Hollenbeck M, Makris N, Insausti R, Ding SL, Dickerson BC (2015) Large-scale brain networks of the human left temporal pole: a functional connectivity MRI study. Cereb Cortex 25:680-702. CrossRef Medline

Patterson K (2007) The reign of typicality in semantic memory. Philos Trans R Soc Lond B Biol Sci 362:813-821. CrossRef Medline

Penny WD, Stephan KE, Mechelli A, Friston KJ (2004) Comparing dynamic causal models. Neuroimage 22:1157-1172. CrossRef Medline

Penny WD, Stephan KE, Daunizeau J, Rosa MJ, Friston KJ, Schofield TM, Leff AP (2010) Comparing families of dynamic causal models. PLoS Comput Biol 6:e1000709. CrossRef Medline

Richardson FM, Seghier ML, Leff AP, Thomas MS, Price CJ (2011) Multiple routes from occipital to temporal cortices during reading. J Neurosci 31:8239-8247. CrossRef Medline

Riesenhuber M, Poggio T (1999) Hierarchical models of object recognition in cortex. Nat Neurosci 2:1019-1025. CrossRef Medline

Roach A, Schwartz MF, Martin N, Grewal RS, Brecher A (1996) The Philadelphia naming test: scoring and rationale. Clin Aphasiol 24:121-133.

Roelfsema PR, Lamme VA, Spekreijse H, Bosch H (2002) Figure-ground segregation in a recurrent network architecture. J Cogn Neurosci 14:525537. CrossRef Medline

Rogers TT, Lambon Ralph MA, Garrard P, Bozeat S, McClelland JL, Hodges JR, Patterson K (2004) Structure and deterioration of semantic memory: a neuropsychological and computational investigation. Psychol Rev 111:205-235. CrossRef Medline

Rudrauf D, David O, Lachaux JP, Kovach CK, Martinerie J, Renault B, Damasio A (2008) Rapid interactions between the ventral visual stream and emotion-related structures rely on a two-pathway architecture. J Neurosci 28:2793-2803. CrossRef Medline

Rytsar R, Fornari E, Frackowiak RS, Ghika JA, Knyazeva MG (2011) Inhibition in early Alzheimer's disease: an fMRI-based study of effective connectivity. Neuroimage 57:1131-1139. CrossRef Medline

Salmelin R, Kujala J (2006) Neural representation of language: activation versus long-range connectivity. Trends Cogn Sci 10:519-525. CrossRef Medline

Sanfeliú MC, Fernández A (1996) A set of 254 Snodgrass-Vanderwart pictures standardized for Spanish: norms for name agreement, image agreement, familiarity and visual complexity. Behav Res Methods Instrum Comput 28:537-555. CrossRef

Schendan HE, Kutas M (2002) Neurophysiological evidence for two processing times for visual object identification. Neuropsychologia 40:931945. CrossRef Medline

Schendan HE, Maher SM (2009) Object knowledge during entry-level categorization is activated and modified by implicit memory after $200 \mathrm{~ms}$. Neuroimage 44:1423-1438. CrossRef Medline

Schurz M, Kronbichler M, Crone J, Richlan F, Klackl J, Wimmer H (2014) Top-down and bottom-up influences on the left ventral occipitotemporal cortex during visual word recognition: an analysis of effective connectivity. Hum Brain Mapp 35:1668-1680. CrossRef Medline

Seacord L, Gross CG, Mishkin M (1979) Role of inferior temporal cortex in interhemispheric transfer. Brain Res 167:259-272. CrossRef Medline

Sebastián N, Martí MA, Carreiras MF, Cuetos F, eds (2000) LEXESP. Léxico informatizado del español. Barcelona: Ediciones de la Universitat de Barcelona.

Seghier ML, Zeidman P, Neufeld NH, Leff AP, Price CJ (2010) Identifying abnormal connectivity in patients using dynamic causal modeling of FMRI responses. Front Syst Neurosci 4:142. CrossRef Medline

Seghier ML, Josse G, Leff AP, Price CJ (2011) Lateralization is predicted by reduced coupling from the left to right prefrontal cortex during semantic decisions on written words. Cereb Cortex 21:1519-1531. CrossRef Medline

Stephan KE, Friston KJ (2007) Models of effective connectivity in neural systems. In: Handbook of brain connectivity: understanding complex systems (Jirsa VK, McIntosh AR, eds), pp 303-326. Berlin: Springer.

Stephan KE, Penny WD, Moran RJ, den Ouden HE, Daunizeau J, Friston KJ (2010) Ten simple rules for dynamic causal modeling. Neuroimage 49: 3099-3109. CrossRef Medline

Steyvers M, Tenenbaum JB (2005) The large-scale structure of semantic networks: statistical analyses and a model of semantic growth. Cogn Sci 29:41-78. CrossRef Medline

Strijkers K, Costa A, Thierry G (2010) Tracking lexical access in speech production: electrophysiological correlates of word frequency and cognate effects. Cereb Cortex 20:912-928. CrossRef Medline

Tang H, Buia C, Madhavan R, Crone NE, Madsen JR, Anderson WS, Kreiman G (2014) Spatiotemporal dynamics underlying object completion in human ventral visual cortex. Neuron 83:736-748. CrossRef Medline

Taulu S, Hari R (2009) Removal of magnetoencephalographic artifacts with temporal signal-space separation: demonstration with single-trial auditory-evoked responses. Hum Brain Mapp 30:1524-1534. CrossRef Medline

Thorpe S, Fize D, Marlot C (1996) Speed of processing in the human visual system. Nature 381:520-522. CrossRef Medline

Trapp S, Bar M (2015) Prediction, context, and competition in visual recognition. Ann N Y Acad Sci 1339:190-198. CrossRef Medline

Turken AU, Dronkers NF (2011) The neural architecture of the language comprehension network: converging evidence from lesion and connectivity analyses. Front Syst Neurosci 5:1. CrossRef Medline

Ungerleider JT, Mishkin M (1982) Two cortical visual systems. In: Analysis of visual behavior (Ingle DJ, Goodale MA, Mansfiled RJW, eds), pp 549 586. Cambridge, MA: MIT

Von Der Heide RJ, Skipper LM, Klobusicky E, Olson IR (2013) Dissecting the uncinate fasciculus: disorders, controversies and a hypothesis. Brain 136:1692-1707. CrossRef Medline

Walther DB, Koch C (2007) Attention in hierarchical models of object recognition. Prog Brain Res 165:57-78. CrossRef Medline

Wilson SM, Isenberg AL, Hickok G (2009) Neural correlates of word production stages delineated by parametric modulation of psycholinguistic variables. Hum Brain Mapp 30:3596-3608. CrossRef Medline

Wokke ME, Sligte IG, Steven Scholte H, Lamme VA (2012) Two critical periods in early visual cortex during figure-ground segregation. Brain Behav 2:763-777. CrossRef Medline

Woodhead ZV, Barnes GR, Penny W, Moran R, Teki S, Price CJ, Leff AP (2014) Reading front to back: MEG evidence for early feedback effects during word recognition. Cereb Cortex 24:817-825. CrossRef Medline

Woollams AM (2012) Apples are not the only fruit: the effects of concept typicality on semantic representation in the anterior temporal lobe. Front Hum Neurosci 6:85. CrossRef Medline

Woollams AM, Cooper-Pye E, Hodges JR, Patterson K (2008) Anomia: a doubly typical signature of semantic dementia. Neuropsychologia 46: 2503-2514. CrossRef Medline

Wright P, Randall B, Clarke A, Tyler LK (2015) The perirhinal cortex and conceptual processing: effects of feature-based statistics following damage to the anterior temporal lobes. Neuropsychologia. Advance online publication. CrossRef Medline

Wu CT, Crouzet SM, Thorpe SJ, Fabre-Thorpe M (2015) At 120 ms you can spot the animal but you don't yet know it's a dog. J Cogn Neurosci 27: 141-149. CrossRef Medline

Xu M, Wang T, Chen S, Fox PT, Tan LH (2015) Effective connectivity of brain regions related to visual word recognition: an fMRI study of Chinese reading. Hum Brain Mapp. Advance online publication. CrossRef Medline 